\title{
Predicting the Habitat Suitability of a Potential Invasive Fern, Cyclosorus afer in Lafia, Nigeria using Species Distribution Modelling
}

\author{
G.F. Akomolafe ${ }^{1,2}$ and Z. Rahmad ${ }^{1,3^{*}}$ \\ ${ }^{1}$ School of Biological Sciences, Universiti Sains Malaysia, 11800, \\ Gelugor, Pulau Pinang, Malaysia. \\ ${ }^{2}$ Department of Botany, Federal University Lafia, \\ PMB 146, Lafia, Nigeria \\ ${ }^{3}$ Center for Global Sustainability Studies (CGSS), level 5, Hamzah Sendut Library 1, \\ Universiti Sains Malaysia, 11800, Pulau Pinang, Malaysia
}

\begin{abstract}
The vast colonisation of some wetlands by Cyclosorus afer in Lafia, Nigeria has been a serious concern to ecologists and indigenous dwellers. In this study, we used the Maximum Entropy (Maxent) modelling technique to predict the habitat suitability of this fern in Lafia, Nigeria. We obtained the presence data of this fern in three already invaded wetlands of size $500 \times 500 \mathrm{~m}^{2}$ each using multiple 200m transect. Bioclimatic and elevation variables which were obtained from different databases were imputed into the model as predictor variables of C. afer. After that, the Maxent model was run with $70 \%$ of the presence data as training and $30 \%$ as test data. Our model result revealed that the area under the curve for receiver operating characteristics of training is 0.847 while and test data is 0.970 . The model's sensitivity was observed to be $100 \%$. The model was assessed based on a jackknife test of individual contributions of each predictor variable to the model. Therefore, the environmental predictors of the occurrence of $C$. afer in this study area include precipitation seasonality, Precipitation of driest quarter, precipitation of coldest quarter and elevation. This model could be described as accurate, and the occurrence of $C$. afer in Lafia, Nigeria, is influenced by limiting environmental factors.
\end{abstract}

Keywords: Cyclosorus afer; fern; invasion; Lafia; Maxent; modelling

\section{INTRODUCTION}

The pattern of successful invasions of invasive plants has always been by occupying new geographical locations, geometrical growth increase, rapid spread, eventually posing threats to the native biodiversity and economy of the areas invaded (Galil et al., 2015; Coll et al., 2010; Galil, 2008). This is why monitoring and predicting the habitats suitable for their spread is very important to ecologists (Coro et al., 2018). Apart from the prediction of habitat suitability, concerted efforts towards assessments of their potential negative environmental effects and control measures are highly recommended (Hulme, 2006). Usually, complete eradication of already established invasive plants has proved to be impossible (Myers et al., 2000). Thus, early detection and prevention of introduction, spread and future establishments of potentially invasive plants are the most effective ways of salvaging the environment from the menace of plant invasion (Leung et al., 2002). Over the years, the use of ecological niche models (ENMs) or species distribution models (SDMs) in predicting invasive species distributions has generated a lot of interests among ecologists, particularly using different techniques in establishing habitats suitability differences between the

*Corresponding author's e-mail: rahmadz@usm.my 
native and invaded regions of invasive plants (Guisan et al., 2014; Leidenberger et al., 2015; Peterson, 2003).

The influence of climate change on the distribution of invasive species has been a widely used approach in most ENMs (Thuiller et al., 2005; Sax et al., 2007). These models usually integrate the relationship between species occurrence data and a lot of environmental factors known as predictors to simulate the distribution of invasive species which can be extrapolated into a particular geographical area (Mellin et al., 2016; Carlos-Júnior et al., 2015; Coro et al., 2018). Most commonly used ENMs can be categorised into the statistical model (Bidegain et al., 2015; Ficetola et al., 2007), machine learning model (Peterson and Robins, 2003) and envelope-based model (Jeschke and Strayer, 2008). One of the most commonly used presence-only ENMs is the maximum entropy (MAXENT) machine learning model (West et al., 2016; Ficetola et al., 2007). Most introduced plant species do tend to become invasive after a few years of introduction into new geographical locations. This is as a result of the prolonged lag phase which may make it difficult for their invasiveness to be detected earlier, hence the need for periodic assessments of these introduced plants (Crooks et al., 1999).

Predictions of the ecological factors influencing the establishments of potentially invasive plants which are a function of the climatic similarities between native and invaded communities are very important in preventing their future spread and establishments (Thuiller et al., 2005; Richardson and Thuiller, 2007; Welk et al., 2002). Modelling the climatic niches of invasive plants using their native occurrence data and projecting their spread on a larger scale in order to determine areas with a higher probability of occurrence has been made easier with the recently developed modelling approaches (Thuiller et al., 2005). Apart from climatic factors, other factors, especially biotic interactions of species, contribute to understanding the mechanisms behind invasion success of many plants (Stohlgren and Schnase, 2006). Therefore, in this study, we aimed at predicting the habitat suitability of a wetland fern Cyclosorus afer (Christ) Ching, also known as Pneumatopteris afra (Christ) Holttum in Lafia, Nigeria, using Maximum Entropy (Maxent) as the species distribution model. This fern has displayed its invasive potential in many wetlands in Lafia, Nigeria, by forming large covering and disrupting the flow of water (Akomolafe et al., 2017).

\section{MATERIALS AND METHODS}

\section{A. Study Area and Sampling Technique}

The study was carried out at Lafia, Nigeria. Lafia lies between latitude $8^{\circ} 25^{\prime} 40^{\circ} \mathrm{N}$ to $8^{\circ} 34^{\prime} 15^{\circ} \mathrm{N}$ and longitude $8^{\circ} 24^{\prime} 25^{\circ} \mathrm{E}$ to $8^{\circ} 39^{\prime} 19^{\circ} \mathrm{E}$ of North Central Nigeria. Rainy season in Lafia is usually between May to September and dry season occurs from October to April of the next year. The predominant vegetation in Lafia includes woody shrubs, grasses and few trees which could be described as Southern Guinea Savannah. Lafia is known for farming activities, and some of the crops cultivated include cereals, vegetables, tubers and economical tree (Akomolafe et al., 2018). Very little has been known about the threats of invasive plants in Lafia. Invasive plants such as Chromolaena odorata, Sida acuta and Tithonia diversifolia are only found by the roadsides. We chose three invaded wetlands in Lafia, Nigeria, as sampling sites. These wetlands have been heavily colonised by C. afer, thereby forming homogeneous colonies. $500 m$ x 500m plot was demarcated in each site for the study. A minimum distance of $1000 \mathrm{~m}$ was maintained between each site.

\section{B. Spatial data mapping and Distribution Modelling}

\section{Presence data}

The local presence data of $C$. afer in the three sites were taken on the field by marking the spatial reference points using a GPS device (Garmin Etrext 10). This was done when the biomass of $C$. afer has reached the peak of growth in all the sites. We maintained a minimum distance of $20 \mathrm{~m}$ between each reference point of C. afer along 200m transect at each site. A total of 95 presence spatial reference points were documented in all the study sites. 


\section{Environmental variables used for the model}

Bioclimatic and elevation variables were input into the model as environmental variables. These variables have been reported to influence the productivity of plant species (Lennon et al., 2000). Out of 19 bioclimatic variables, we selected 5 through multicollinearity test of linear regression model using IBM SPSS 24 (Table 1). These variables were also chosen based on their importance in the species ecology. Bioclimatic and elevation variables were taken from the WorldClim Version 2.0 dataset (Hijmans et al., 2017). Global digital elevation model was obtained at USGS Earth Explorer. All these variables were extracted individually by superposing them on Lafia boundary map using ArcMap 10.2.1 tools. These together with the species presence data were converted into ASCII format for input into the Maxent model, making sure they have a similar geographical boundary, processing extent and cell size.

\section{Species distribution modelling}

We used a maximum entropy (Maxent) model to predict the habitat suitability and distribution of C. afer in Lafia, Nigeria. Maxent model has been tested and reported to be a reliable model that utilises few occurrence data (Phillips et al., 2006; Wisz et al., 2008; Guisan et al., 2007). Maxent can predict species niche by determining the probability distributions closest to uniform (maximum entropy) from the pool of species occurrence data and environmental variables (Phillips et al., 2006). Maxent 3.4.1 software was used to actualise this. The species presence data were divided into training and test proportions. We used $30 \%$ of it as test data, while the remaining $70 \%$ was used as training data. The environmental variables were loaded into the model as ASCII file type.

\section{Assessment of individual variables contributions}

The contribution of an individual environmental variable to the model was assessed using the Jackknife test in the Maxent software. The Jackknife test sequentially isolated each variable out of the model and produced a model using other variables. It also produced a model using only the isolated variable alone.

\section{Evaluation of the Model}

The area under the curve (AUC) of the Receiver Operating Characteristics (ROC) curve plotted by the Maxent model was used to evaluate the model. Also, the sensitivity of occurrence points was determined (Anderson et al., 2003).

$$
I-\text { sensitivity }=\frac{\text { Correctly predicted points }}{\text { Observed presense points }} \times 100
$$

\section{RESULTS}

Figure 1 shows the omission/commission rate, which gives an overview of predicted areas invaded by $C$. afer. Both omission and predicted areas are products of a threshold dependent binomial test representing areas suitable or not suitable for C. afer. For both training and test data, the omission rate is o. Maxent prediction as compared with random prediction is revealed by the receiver operating characteristics (ROC) curve, whereby the area under the curve (AUC) for training and test data are 0.847 and 0.970 , respectively. The AUC for random prediction is 0.5 (Figure 2).

The Maxent model showed that all the local presence points of C. afer are found within the predicted areas of high probability (Figure 3). Considering this model, areas with higher predictions are represented by warmer colours, training data are represented by white dots, and test data are denoted by violet dots. This Maxent model has 100\% sensitivity for the occurrence of $C$. afer since the predicted and observed points are the same. The predicted spatial extent of C. afer in Lafia, Nigeria, is between $8^{\circ} 21^{\prime} 0^{\prime \prime}$ $8^{\circ} 55^{\prime} \mathrm{o}^{\prime \prime} \mathrm{N}$ and $8^{\circ} 5^{\prime} \mathrm{o}^{\prime \prime}-8^{\circ} 55^{\prime} \mathrm{O}^{\prime \prime} \mathrm{E}$. The total area predicted was found to be $1784.07 \mathrm{Km}^{2}$ (Figure 4).

The predictor variable that showed the highest gain when isolated is bio17, i.e. precipitation of driest quarter, which has the most useful information by itself. The predictor variable that decreases the gain the most when it is omitted is elevation (Figure $5 \mathrm{a}$ and b). The precipitation of the warmest quarter (bio18) is the only variable which did not produce any gain. Therefore, the most important predictor 
variables of $C$. afer distribution in Lafia whose AUC values are greater than 0.5 include precipitation seasonality (bio15), Precipitation of the driest quarter (bio17), precipitation of coldest quarter (bio19) and elevation (Figure 5c).

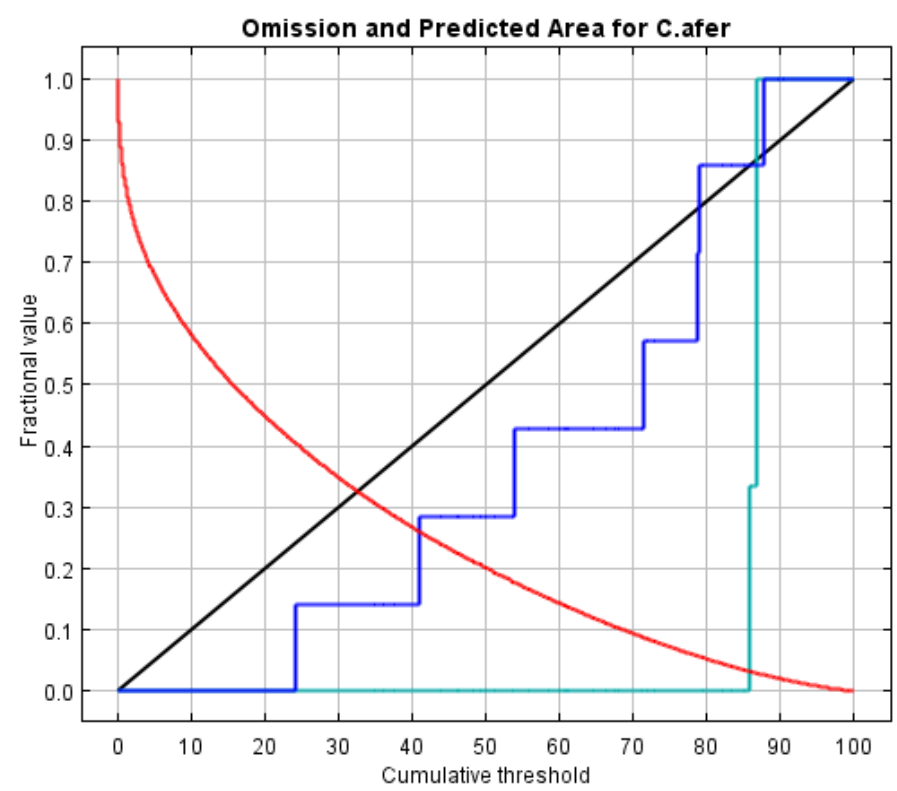

Faction of background predicted Omission on training samples $=$ Omission on test samples : Predicted omission -

Figure 1. The Omission and predicted area

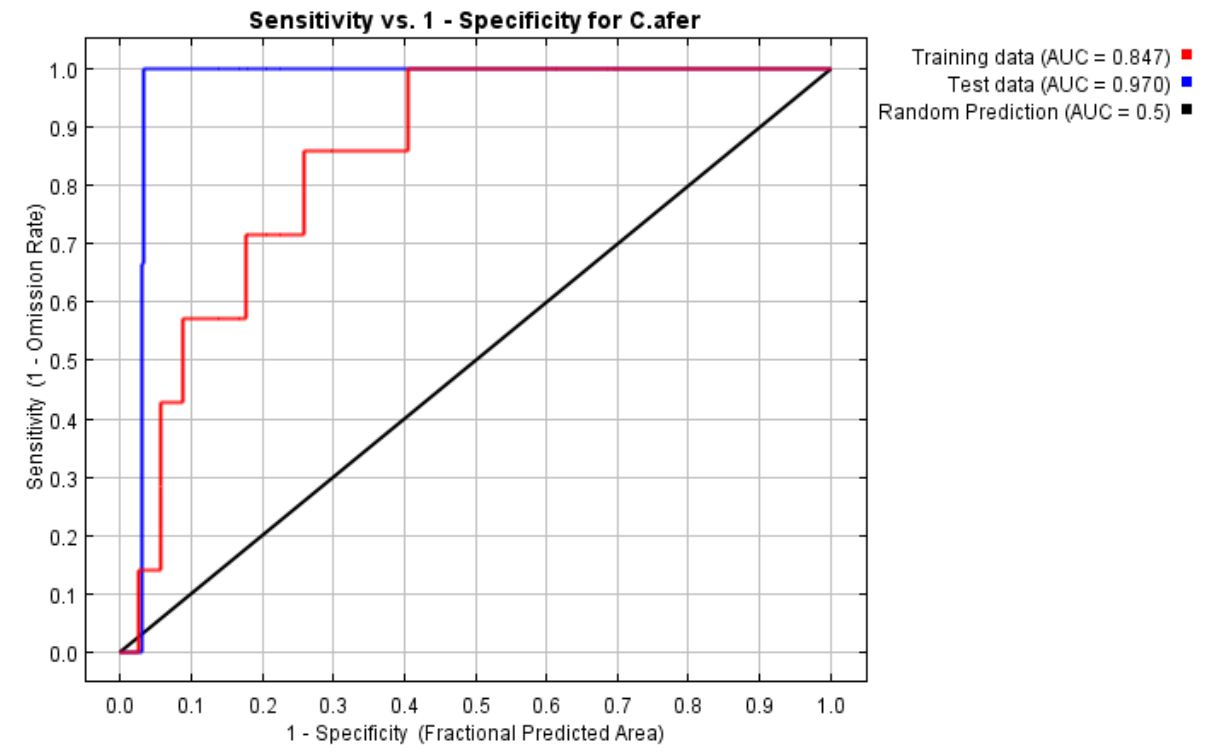

Figure 2. The Receiver operating characteristics (ROC) curve of the training and test data 


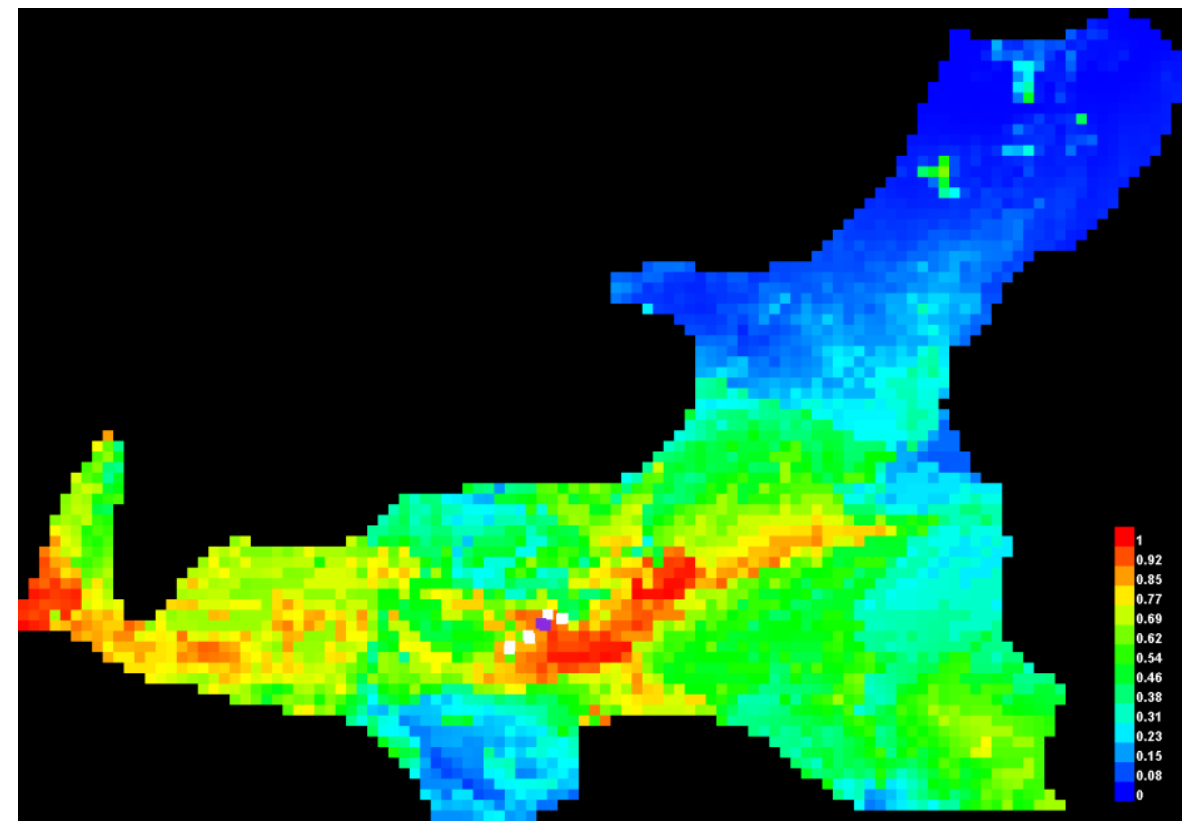

Figure 3. The Maxent model of C. afer distribution in Lafia, Nigeria.

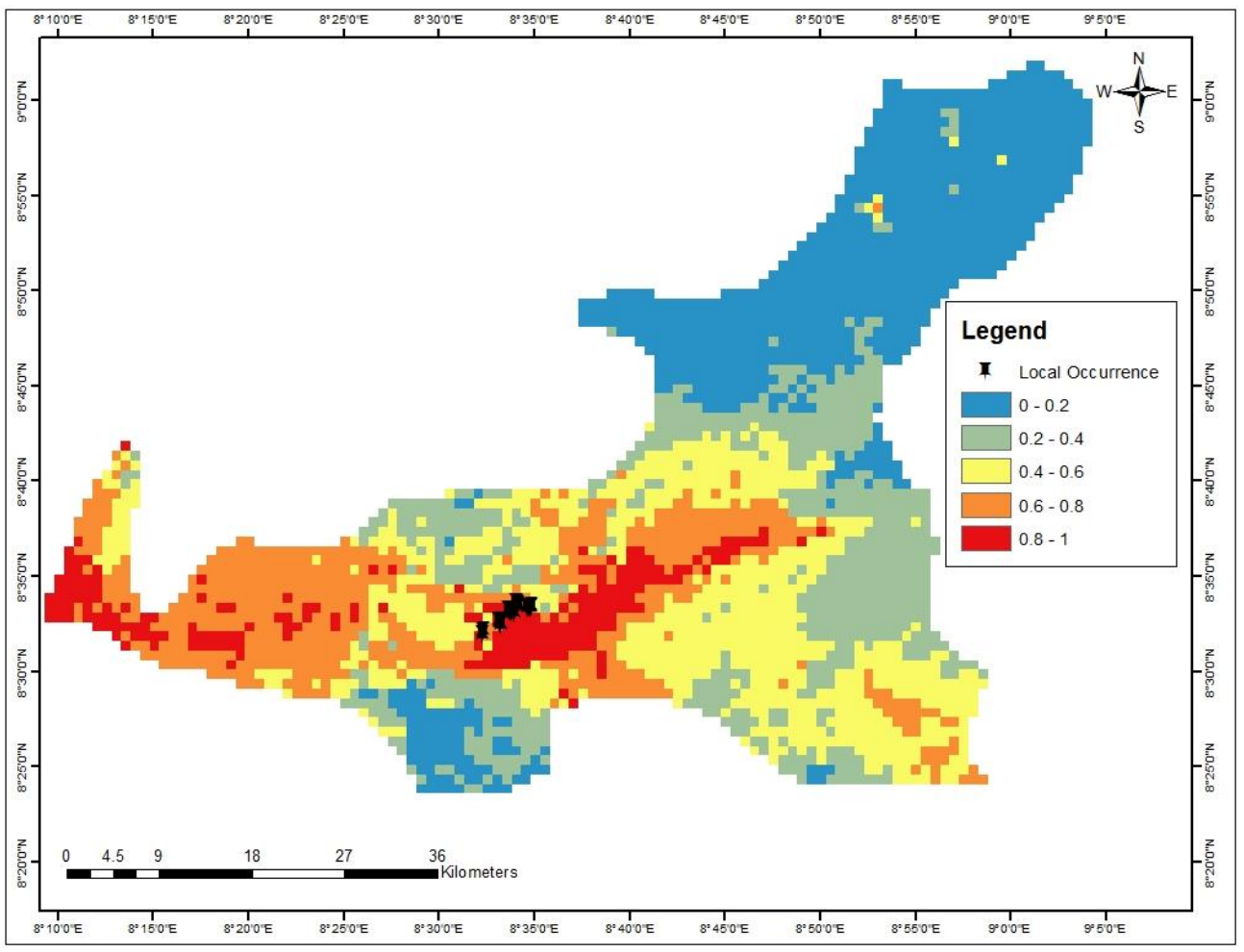

Figure 4. The species distribution probability map of C. afer in Lafia, Nigeria 


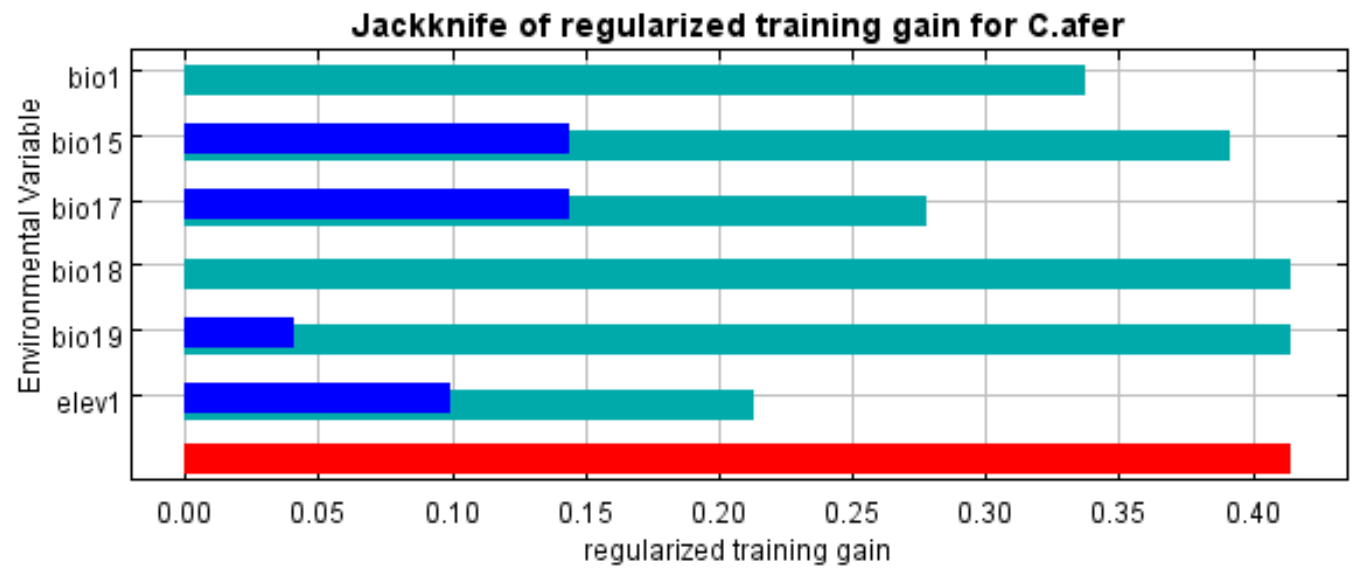

Without variable With only variable $\mathbf{m}$ With all variables $=$

(a)

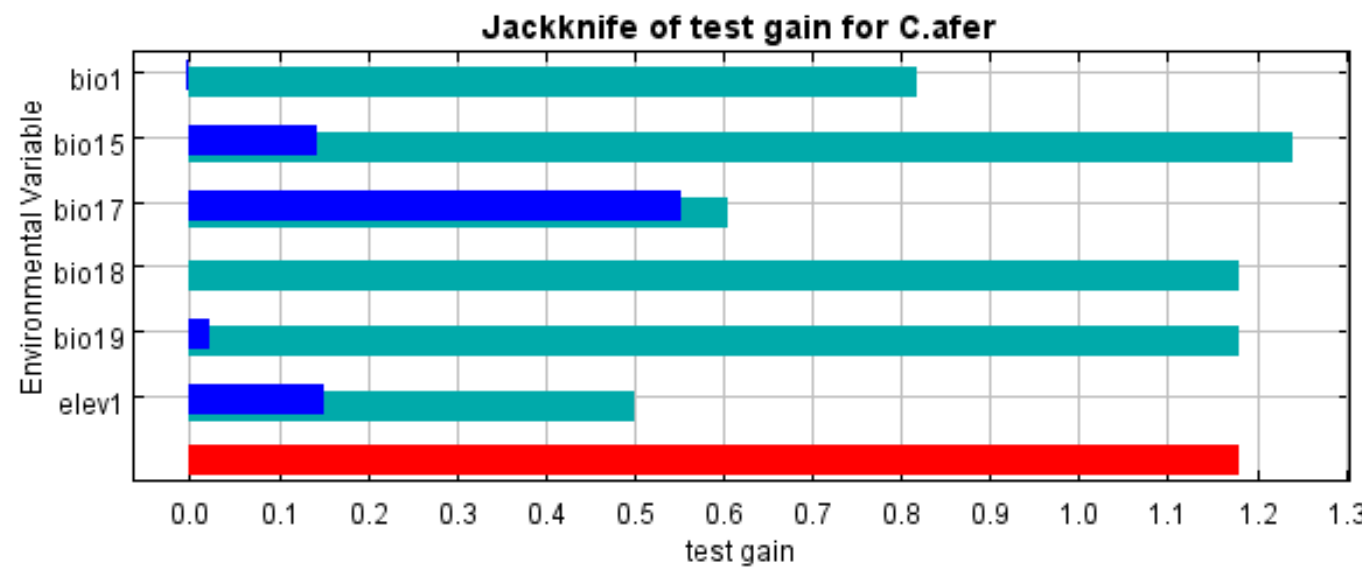

Without variable With only variable With all variables

(b)

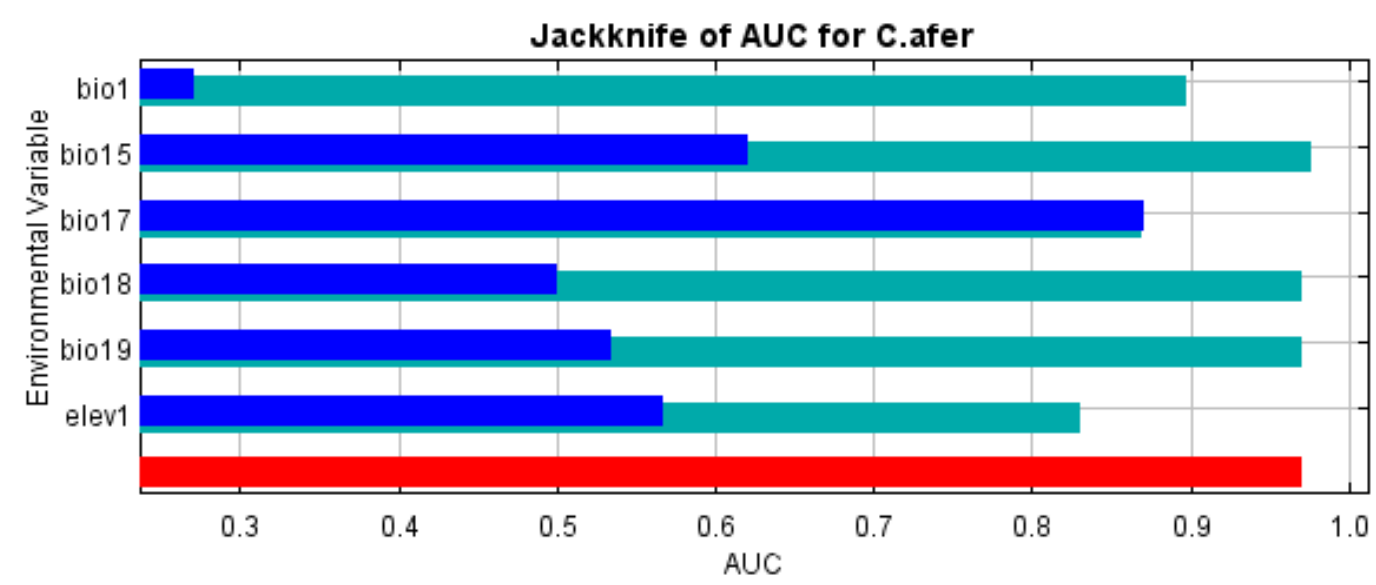

Without variable With only variable With all variables

(c)

Figure 5. Jackknife plot for (a) training gain (b) test gain (c) AUC of C. afer 
Table 1: Environmental variables used in the model

\begin{tabular}{|c|l|l|}
\hline S/N & \multicolumn{1}{|c|}{ Code } & \multicolumn{1}{c|}{ Description } \\
\hline 1 & Elevation & Elevation \\
\hline 2 & Bio1 & Annual mean temperature \\
\hline 3 & Bio15 & $\begin{array}{l}\text { Precipitation seasonality } \\
\text { (Coefficient of Variation) }\end{array}$ \\
\hline 4 & Bio17 & Precipitation of driest quarter \\
\hline 5 & Bio18 & Precipitation of warmest quarter \\
\hline 6 & Bio19 & Precipitation of coldest quarter \\
\hline
\end{tabular}

\section{DISCUSSION}

The prediction of habitat suitability of C. afer in this study was based primarily on the influence of bioclimatic factors which usually play significant roles in species establishments (Woodward et al., 2004; Welk et al., 2002; Roura-Pascual et al., 2004). Although, some other factors such as biotic interactions, disturbances and soil factors are also key determinants of species distributions (Willis and Whittaker, 2002). The impact of climatic factors on the distribution of invasive plants is such that these plants can only be established in areas with no climatic barriers to their growth and reproduction (Scott and Panetta, 1993). Our Maxent model predictions performed better than random prediction due to the higher area under the curve (AUC) of both training and test data as compared with random. Invariably, this is an indication of higher accuracy and sensitivity of the Maxent model (Anderson et al., 2003) and this also means that $C$. afer exhibited a high tolerance to environmental factors (Thuiller et al., 2005). The predicted geographical extent of spread of $C$. afer which is almost half of the total land cover in Lafia is worrisome and should be a thing of concern to environmentalists as it has implications for future loss of biodiversity in the area.

The positive relationship established by the occurrence of C. afer and precipitation of the driest quarter in this model means that areas in Lafia with high precipitations during the driest three months of the year (January - March) will have a high probability of occurrence of $C$. afer. On the contrary, from our model, C. afer exhibited a negative relationship with precipitation of coldest quarter, precipitation seasonality and elevation. This shows that areas with a low amount of precipitation in the coldest three months of the year, low precipitation seasonality and low elevation will have a high probability of occurrence of $C$. afer. All these predictors can be described as limiting environmental factors determining the occurrence and distribution of $C$. afer in the study area (Austin, 2007).

\section{CONCLUSION}

In comparison with random predictions, our Maxent model is more accurate. Occurrence and distribution of $C$. afer in Lafia, Nigeria is influenced by limiting environmental factors. Areas in Lafia having similar environmental ranges are more prone to the risk of $C$. afer invasion in the future. This, therefore, means that government and ecologists should devise proper means of curbing the further spread of this plant on wetlands in Lafia, Nigeria.

\section{ACKNOWLEDGEMENTS}

This study was funded by Nigerian Government Tertiary Education Trust Fund (TETFund) ASTD PhD Grant (FUL/REG/TETfund/oo2/VOL.II/182) and USM research Grant 1001/PBIOLOGI/811330.

\section{REFERENCES}

[1] Akomolafe, G, Oloyede, F \& Chukwu, A 2017, 'Proximate Composition And Preliminary Allelopathic Effect Of A Tropical Fern, Cyclosorus Afer On Oryza Sativa', Scientia, vol. 20, pp. 81-85.
[2] Akomolafe, G, Terna, T \& Okogbaa, J 2018, 'Occurrence and Growth Inhibitory Activity of Striga hermonthica (Delile) Benth on Sorghum bicolor (L.) Moench in Lafia, Nigeria', Nigerian 
Journal of Basic and Applied Science, vol. 26, pp. 65-69.

[3] Anderson, RP, Lew, D \& Peterson, AT 2003, 'Evaluating predictive models of species' distributions: criteria for selecting optimal models', Ecological Modelling, vol. 162, pp. 211232.

[4] Austin, M 2007, 'Species distribution models and ecological theory: a critical assessment and some possible new approaches', Ecological Modelling, vol. 200, pp. 1-19.

[5] Bidegain, G, Bárcena, JF, García, A \& Juanes, JA 2015, 'Predicting coexistence and predominance patterns between the introduced Manila clam (Ruditapes philippinarum) and the European native clam (Ruditapes decussatus)', Estuarine, Coastal and Shelf Science, vol. 152, pp. 162-172.

[6] Carlos-Júnior, L, Barbosa, N, Moulton, T \& Creed, J 2015, 'Ecological Niche Model used to examine the distribution of an invasive, non-indigenous coral', Marine environmental research, vol. 103, pp. $115-124$.

[7] Coll, M, Piroddi, C, Steenbeek, J, Kaschner, K, Lasram, FBR, Aguzzi, J, Ballesteros, E, Bianchi, CN, Corbera, $\mathrm{J} \&$ \& Dailianis, $\mathrm{T}$ 2010, 'The biodiversity of the Mediterranean Sea: estimates, patterns, and threats', PloS one, vol. 5, pp. e11842.

[8] Coro, G, Vilas, LG, Magliozzi, C, Ellenbroek, A, Scarponi, P \& Pagano, P 2018, 'Forecasting the ongoing invasion of Lagocephalus sceleratus in the Mediterranean Sea', Ecological Modelling, vol. 371, pp. 37-49.

[9] Crooks, JA, Soulé, ME \& Sandlund, O 1999, 'Lag times in population explosions of invasive species: causes and implications', Invasive species and biodiversity management', pp. 103-125.

[10] Ficetola, GF, Thuiller, W \& Miaud, C 2007, 'Prediction and validation of the potential global distribution of a problematic alien invasive species-the American bullfrog', Diversity and distributions, vol. 13, pp. 476-485.

[11] Galil, B 2008, Alien species in the Mediterranean Sea-which, when, where, why? Challenges to Marine Ecosystems’. Springer.

[12] Galil, BS, Boero, F, Campbell, ML, Carlton, JT, Cook, E, Fraschetti, S, Gollasch, S, Hewitt, CL, Jelmert, A \& Macpherson, E 2015, 'Double trouble: the expansion of the Suez Canal and marine bioinvasions in the Mediterranean Sea', Biological Invasions, vol. 17, pp. 973-976.

[13] Guisan, A, Petitpierre, B, Broennimann, O, Daehler, C \& Kueffer, C 2014, 'Unifying niche shift studies: insights from biological invasions', Trends in ecology \& evolution, vol. 29, pp. 260-269.

[14] Guisan, A, Zimmermann, NE, Elith, J, Graham, CH, Phillips, S \& Peterson, AT 2007, 'What Matters For Predicting The Occurrences Of Trees: Techniques, Data, Or Species characteristics?', Ecological Monographs, vol. 77, pp. 615-630.

[15] Hulme, PE 2006, 'Beyond control: wider implications for the management of biological invasions', Journal of Applied Ecology, vol. 43, pp. $835-847$

[16] Jeschke, JM \& Strayer, DL 2008, 'Usefulness of bioclimatic models for studying climate change and invasive species', Annals of the New York Academy of Sciences, vol. 1134, pp. 1-24.

[17] Leidenberger, S, Obst, M, Kulawik, R, Stelzer, K, Heyer, K, Hardisty, A \& Bourlat, SJ 2015, 
'Evaluating the potential of ecological niche modelling as a component in marine nonindigenous species risk assessments', Marine pollution bulletin, vol. 97, pp. 470-487.

[18] Leung, B, Lodge, DM, Finnoff, D, Shogren, JF, Lewis, MA \& Lamberti, G 2002, 'An ounce of prevention or a pound of cure: bioeconomic risk analysis of invasive species', Proceedings of the Royal Society of London B: Biological Sciences, vol. 269, pp. 2407-2413.

[19] Mellin, C, Lurgi, M, Matthews, S, Macneil, MA, Caley, M, Bax, N, Przeslawski, R \& Fordham, D 2016, 'Forecasting marine invasions under climate change: Biotic interactions and demographic processes matter', Biological Conservation, vol. 204, pp. 459-467.

[20] Myers, JH, Simberloff, D, Kuris, AM \& Carey, JR 2000, 'Eradication revisited: dealing with exotic species', Trends in ecology \& evolution, vol. 15, pp. 316-320.

[21] Peterson, AT 2003, 'Predicting the geography of species' invasions via ecological niche modeling', The quarterly review of biology, vol. 78, pp. 419433.

[22] Peterson, AT \& Robins, CR 2003, 'Using ecological-niche modeling to predict barred owl invasions with implications for spotted owl conservation', Conservation Biology, vol. 17, pp. $1161-1165$.

[23] Phillips, SJ, Anderson, RP \& Schapire, RE 2006, 'Maximum entropy modeling of species geographic distributions', Ecological Modelling, vol. 190, pp. 231-259.

[24] Richardson, DM \& Thuiller, W 2007, 'Home away from home-objective mapping of high-risk source areas for plant introductions', Diversity and Distributions, vol. 13, pp. 299-312.

[25] Roura-Pascual, N, Suarez, AV, Gómez, C, Pons, P, Touyama, Y, Wild, AL \& Peterson, AT 2004, 'Geographical potential of Argentine ants (Linepithema humile Mayr) in the face of global climate change', Proceedings of the Royal Society of London B: Biological Sciences, vol. 271, pp. 2527-2535.

[26] Sax, DF, Stachowicz, JJ, Brown, JH, Bruno, JF, Dawson, MN, Gaines, SD, Grosberg, RK, Hastings, A, Holt, RD \& Mayfield, MM 2007, 'Ecological and evolutionary insights from species invasions', Trends in ecology \& evolution, vol. 22, pp. 465471.

[27] Scott, J \& Panetta, F 1993, 'Predicting the Australian weed status of southern African plants', Journal of Biogeography, pp. 87-93.

[28] Stohlgren, TJ \& Schnase, JL 2006, 'Risk analysis for biological hazards: what we need to know about invasive species', Risk Analysis: An International Journal, 26, 163-173.

[29] Thuiller, W, Lavorel, S \& Araújo, MB 2005, 'Niche properties and geographical extent as predictors of species sensitivity to climate change', Global Ecology and Biogeography, vol. 14, pp. 347-357.

[30] Welk, E, Schubert, K \& Hoffmann, MH 2002, 'Present and potential distribution of invasive garlic mustard (Alliaria petiolata) in North America', Diversity and Distributions, vol. 8, pp. 219-233.

[31] West, AM, Kumar, S, Brown, CS, Stohlgren, TJ \& Bromberg, J 2016, 'Field validation of an invasive species Maxent model', Ecological informatics, vol. 36, pp. 126-134. 
[32] Willis, KJ \& Whittaker, RJ 2002, 'Species diversity--scale matters', Science, vol. 295, pp. 1245-1248.

[33] Wisz, MS, Hijmans, R, Li, J, Peterson, AT, Graham, C, Guisan, A \& Group, NPSDW 2008, 'Effects of sample size on the performance of species distribution models', Diversity and distributions, vol. 14, pp. 763-773.

[34] Woodward, FI, Lomas, MR \& Kelly, CK 2004, 'Global climate and the distribution of plant biomes', Philosophical Transactions of the Royal Society of London B: Biological Sciences, vol. 359, pp. $1465-1476$. 